\title{
Lung Tissue Elastin Composition in Newborn Infants with the Respiratory Distress Syndrome and Other Diseases
}

\author{
Hugh E. Evans, Stephen Keller, and Ines Mandl \\ From the Department of Pediatrics and the Department of Obstetrics and \\ Gynecology, Columbia University College of Physicians and Surgeons, \\ New York 10032
}

\begin{abstract}
A в S T R A C T Amino acid analysis of human fetal lung elastin was undertaken in 49 instances of live-born neonates, ranging from $380 \mathrm{~g}$ to full term, and in 3 abortuses of 12-14 wk gestation. The data suggest that formation of the cross-linking agents, desmosine and isodesmosine, occurs early, between 14 and $22 \mathrm{wk}$. The ratio of neutral to charged amino acids remains low until the 36th wk when it attains adult levels. The composition of elastin was independent of sex and duration of survival. In three neonatal pulmonary diseases (respiratory distress syndrome, atelectasis, and hemorrhage) ratios were significantly lower than those found in nondiseased lungs. This may be a reflection of immaturity or may be a predisposing factor in neonatal lung disease. The latter hypothesis is attractive and receives indirect support from the association of a more polar elastin with other diseases, including adult emphysema and atheromatous aortic change.

Our finding of relatively high polarity in elastin from human fetal lung is consistent with previous observations in a variety of fetal organs of other species.
\end{abstract}

\section{INTRODUCTION}

A major cause of neonatal death, accounting for about 12,000 fatalities a year in the U.S. alone, is the idiopathic respiratory distress syndrome $\left(\mathrm{RDS}^{1}\right.$ or hyaline membrane disease). Fetal immaturity predisposes to this condition, and the high incidence of affected neonates delivered before the $32 \mathrm{nd}$ wk of gestation is attributed, in part, to incomplete surfactant synthesis. We have observed previously $(1,2)$ that the amino acid com-

\footnotetext{
Dr. Evans' present address is: Department of Pediatrics, Jewish Hospital and Medical Center of Brooklyn, New York 11238.

Received for publication 4 September 1973 and in revised form 22 January 1974.

${ }^{1}$ Abbreviations used in this paper: $\mathrm{NP} / \mathrm{P}$, the sum of the most prevalent nonpolar amino acids divided by the sum of the charged, polar amino acids; RDS, respiratory distress syndrome.
}

position of elastin isolated from the lung of neonates who died with RDS was, in many cases, significantly different from that of mature lung elastin. In the present study, elastin from the lungs of 49 newborns, who died within the first 4 days of life, was compared on the basis of gestational age and clinical or pathological diagnosis.

\section{METHODS}

Lung tissue was obtained post-mortem from 15 premature infants with clinical, biochemical, and histological evidence of RDS (birth weights ranging from 580 to $2,150 \mathrm{~g}$ ), 5 with meconium aspiration $(1,644$ to $4,082 \mathrm{~g}), 16$ newborn infants with atelectasis ( 380 to $2,370 \mathrm{~g}$ ), 4 with pulmonary hemorrhage ( 600 to $2,780 \mathrm{~g}$ ), and 9 newborns with normal pulmonary histology but with central nervous system and other anomalies (1,670 to $4,400 \mathrm{~g})$.

Microscopic examination of each lung was reviewed by an experienced pediatric pathologist (Dr. Weiner LeBlanc, Department of Pediatrics, Harlem Hospital Center), and one of the authors (H. E.), without knowledge of the elastin analysis. Atelectasis was the term used in cases in which this finding was not accompanied by hyaline membrane formation. Hyaline membrane disease was diagnosed if hyaline membranes were identified as well as other findings, such as atelectasis. These cases also had the appropriate clinical and $\mathbf{x}$-ray findings of hyaline membrane disease.

The lung tissue was frozen, without preservatives, at $-10^{\circ} \mathrm{C}$, washed in $1 \mathrm{M} \mathrm{NaCl}$ for $24 \mathrm{~h}$, defatted with $n$ butyl alcohol at $0^{\circ} \mathrm{C}$ and acetone at $-10^{\circ}$, and the elastin extracted by an adaptation of the method of Lansing, Rosenthal, Alex, and Dempsey (3) by boiling with $0.1 \mathrm{~N}$ $\mathrm{NaOH}$ at $100^{\circ} \mathrm{C}$ for $45 \mathrm{~min}$. The isolated elastin was lyophilized and aliquots hydrolyzed with $6 \mathrm{~N} \mathrm{HCl}$. Amino acid composition was determined on a Technicon amino acid analyzer (Technicon Instruments Corp., Tarrytown, N. Y.) or, with suitable modification to resolve desmosine and isodesmosine, on a Beckman 120B analyzer (Beckman Instruments, Inc., Fullerton, Calif.). Low proportions of hydroxyproline indicated that collagen removal was complete, and the presence of the cross-linking agents, desmosine and isodesmosine, confirmed the identity of the elastin. 
TABLE I

Lung Elastin Amino Acid Composition of Representative Newborns

\begin{tabular}{|c|c|c|c|c|c|c|c|c|c|c|c|c|}
\hline $\begin{array}{l}\text { Diagnosis....... } \\
\text { Birth weight-sex.. } \\
\text { Survival time.... }\end{array}$ & $\begin{array}{l}\text { Nonpulm. } \\
.2,230-\mathrm{F} \\
\ldots 72 \mathrm{~h}\end{array}$ & $\begin{array}{l}\text { Nonpulm. } \\
2,700-\mathrm{M} \\
72 \mathrm{~h}\end{array}$ & $\begin{array}{c}\text { RDS } \\
1,235-\mathrm{M} \\
15 \mathrm{~h}\end{array}$ & $\begin{array}{c}\text { RDS } \\
1,270-\mathrm{M} \\
12 \mathrm{~h}\end{array}$ & $\begin{array}{c}\text { RDS } \\
750-F \\
6 \mathrm{hr}\end{array}$ & $\begin{array}{l}\text { Atel. } \\
600-\mathrm{F} \\
1 \mathrm{~h}\end{array}$ & $\begin{array}{l}\text { Atel. } \\
595-\mathrm{F} \\
2 \mathrm{~h}\end{array}$ & $\begin{array}{l}\text { Atel. } \\
2,130-\mathrm{F} \\
36 \mathrm{~h}\end{array}$ & $\begin{array}{l}\text { Pulm. } \\
\text { hem. } \\
2,000-\mathrm{F} \\
48 \mathrm{~h}\end{array}$ & $\begin{array}{l}\text { Pulm. } \\
\text { hem. } \\
600-\mathrm{M} \\
60 \mathrm{~h}\end{array}$ & $\begin{array}{c}\text { Mec. } \\
\text { asp. } \\
1,644-\mathrm{M} \\
6 \mathrm{~h}\end{array}$ & $\begin{array}{c}\text { Mec. } \\
\text { asp. } \\
\text { 1,900-F } \\
3 \mathrm{~h}\end{array}$ \\
\hline \multicolumn{13}{|c|}{ Amino acids residues/ 100 residues } \\
\hline Hydroxyproline & 1.25 & 2.08 & 0.42 & 1.07 & 1.15 & 2.49 & 1.90 & 1.44 & 0.99 & 1.49 & 1.24 & 0.80 \\
\hline Aspartic acid & 0.37 & 1.18 & 5.82 & 2.74 & 1.52 & 3.78 & 7.38 & 3.55 & 3.54 & 1.11 & 1.16 & 2.31 \\
\hline Threonine & 1.25 & 1.40 & 4.15 & 2.17 & 1.58 & 1.82 & 3.92 & 2.23 & 2.82 & 1.45 & 1.36 & 2.07 \\
\hline Serine & 1.02 & 1.24 & 4.54 & 2.48 & 1.68 & 2.35 & 4.77 & 2.47 & 3.35 & 1.36 & 1.31 & 2.96 \\
\hline Glutamic acid & 1.65 & 2.94 & 8.15 & 4.45 & 3.26 & 5.59 & 8.93 & 5.14 & 5.44 & 2.59 & 2.51 & 4.48 \\
\hline Proline & 11.60 & 13.60 & 8.05 & 9.35 & 10.90 & 10.92 & 8.18 & 9.60 & 9.23 & 11.35 & 10.70 & 10.33 \\
\hline Glycine & 30.70 & 29.10 & 16.17 & 26.40 & 27.30 & 30.89 & 21.01 & 27.99 & 23.60 & 29.60 & 29.82 & 26.40 \\
\hline Alanine & 23.80 & 21.40 & 13.59 & 21.30 & 21.70 & 19.35 & 13.40 & 18.71 & 18.25 & 23.07 & 22.70 & 19.32 \\
\hline Valine & 13.05 & 10.60 & 8.20 & 10.50 & 11.50 & 6.28 & 5.47 & 8.35 & 9.37 & 11.42 & 12.04 & 10.20 \\
\hline Isoleucine & 2.62 & 2.17 & 3.64 & 2.73 & 2.74 & 2.29 & 2.74 & 2.82 & 2.78 & 2.49 & 2.63 & 2.73 \\
\hline Leucine & 6.19 & 5.81 & 8.80 & 6.00 & 7.18 & 5.47 & 6.51 & 6.48 & 7.32 & 6.31 & 6.40 & 6.88 \\
\hline Tyrosine & 1.64 & 1.35 & 1.96 & 1.55 & 1.66 & 0.89 & 1.66 & 1.70 & 2.26 & 1.35 & 1.25 & 1.54 \\
\hline Phenylalanine & 2.34 & 2.52 & 3.61 & 2.61 & 2.78 & 2.35 & 2.86 & 2.61 & 2.89 & 2.43 & 2.36 & 2.82 \\
\hline Lysine & 0.77 & 1.46 & 5.01 & 2.47 & 1.97 & 2.52 & 4.61 & 2.84 & 3.00 & 1.40 & 1.50 & 2.40 \\
\hline Histidine & 0.053 & 0.38 & 1.59 & 0.64 & 0.45 & 0.56 & 1.35 & 0.82 & 0.93 & 0.26 & 0.28 & 0.77 \\
\hline Arginine & 0.67 & 1.26 & 4.49 & 2.02 & 1.49 & 2.27 & 5.16 & 2.98 & 2.54 & 0.76 & 1.14 & 1.71 \\
\hline $\begin{array}{l}\text { Desmosine and } \\
\text { isodesmosine }\end{array}$ & 0.26 & 0.19 & 0.06 & 0.15 & 0.18 & 0.16 & 0.12 & 0.085 & 0.14 & 0.18 & 0.23 & 0.16 \\
\hline $\begin{array}{l}\text { Ratio of } \\
\text { nonpolar: polar }\end{array}$ & 25.0 & 11.5 & 2.3 & 6.2 & 9.35 & 5.1 & 2.09 & 4.83 & 4.6 & 13.8 & 12.8 & 6.51 \\
\hline
\end{tabular}

\section{RESULTS}

Complete amino acid analyses of lung elastin isolated from representative cases are listed in Table I. It can be seen that in some of the neonates with low birth weights the relative proportions of polar amino acid residues are greatly increased at the expense of valine, glycine, and alanine. Several of the low birthweight infants died with diagnoses of RDS or atelectasis. Table II and III correlate the observed changes in polarity with gestational age and pulmonary disease, respectively. A factor, NP/P, the ratio of the sum of the most prevalent nonpolar amino acids (glycine, alanine, valine, proline, leucine, and isoleucine) to the sum of the charged polar amino acids (aspartic acid, glutamic acid, lysine, arginine, and histidine) is used as an indicator of the compositional change. In addition, the percentage of the two major elastin cross-links, desmosine and isodesmosine, is shown for the different groups.

The median $\mathrm{NP} / \mathrm{P}$ ratio among the most immature newborns was $5.10(380-900 \mathrm{~g})$; among those in the $1,050-1,900$ - and 2,000-2,370-g range, the median ratios were 6.5 and 5.7. Among the full-term group, the ratio increased to 23. The median desmosine level showed no significant variation in newborns beyond $22 \mathrm{wk}$ of gestation.

The median NP/P ratios varied from 4.8, 9.2, and 9.0 among those with atelectasis, RDS, and pulmonary hemorrhage, respectively, to 12.8 among those with as-

TABLE II

Ratio of Nonpolar to Polar Amino Acids and Residues of Desmosine Plus Isodesmosine Cross-Links in Relationship to Birthweight

\begin{tabular}{|c|c|c|c|c|c|c|c|}
\hline \multirow{2}{*}{$\begin{array}{l}\text { Weight range, } \\
\text { gestational age }\end{array}$} & \multirow{2}{*}{$\begin{array}{c}\text { No. of } \\
\text { cases }\end{array}$} & \multicolumn{3}{|c|}{$\mathrm{NP} / \mathrm{P}$} & \multicolumn{3}{|c|}{ Des + Ides } \\
\hline & & Median & Mean & Range & Median & Mean & Range \\
\hline $\begin{array}{l}380-900 \\
19-26 \mathrm{wk}\end{array}$ & 15 & 5.1 & 7.5 & $1.3-16.2$ & 0.14 & 0.14 & $0.00-0.30$ \\
\hline $\begin{array}{c}1,050-1,900 \\
28-32 \mathrm{wk}\end{array}$ & 18 & 6.5 & 9.5 & $2.1-27.1$ & 0.137 & 0.135 & $0.00-0.27$ \\
\hline $\begin{array}{c}2,000-2,370 \\
33-35 \mathrm{wk}\end{array}$ & 7 & 5.7 & 11.8 & $4.6-25.0$ & 0.15 & 0.16 & $0.08-0.22$ \\
\hline $\begin{array}{c}2,700-4,082 \\
36-40 \mathrm{wk}\end{array}$ & 9 & 23 & 20 & $11.5-28.8$ & 0.17 & 0.17 & $0.13-0.19$ \\
\hline
\end{tabular}


TABLE III

Ratio of Nonpolar to Polar Amino Acids and Residues of Desmosine Plus Isodesmosine Cross-Links in Relationship to Pulmonary Disease

\begin{tabular}{|c|c|c|c|c|c|c|c|c|c|}
\hline \multirow[b]{2}{*}{ Disease category } & \multirow{2}{*}{$\begin{array}{c}\text { No. of } \\
\text { cases }\end{array}$} & \multicolumn{2}{|c|}{ Birthweight } & \multicolumn{3}{|c|}{$\mathrm{NP} / \mathrm{P}$} & \multicolumn{3}{|c|}{ Des + Ides } \\
\hline & & Mean & Range & Median & Mean & Range & Median & Mean & Range \\
\hline Nonpulmonary & 9 & 2,855 & $1,670-4,400$ & 17 & 21.0 & $9.5-28.8$ & 0.17 & 0.17 & $0.13-0.26$ \\
\hline RDS & 15 & 1,224 & $580-2,150$ & 9.2 & 9.7 & $2.1-19.3$ & 0.15 & 0.13 & $0.02-0.21$ \\
\hline Atelectasis & 16 & 1,072 & $380-2,370$ & 4.8 & 6.3 & $1.4-16.5$ & 0.12 & 0.18 & $0.00-0.30$ \\
\hline Aspiration & 5 & 2,063 & $1,644-4,082$ & 12.8 & 14.4 & $3.09-28.7$ & 0.16 & 0.16 & $0.07-0.23$ \\
\hline Hemorrhage & 4 & 1,600 & $600-2,700$ & 9.0 & 9.6 & $2.4-18.2$ & 0.15 & 0.13 & $0.04-0.18$ \\
\hline
\end{tabular}

piration and 17.0 for those without pulmonary disease. The median desmosine levels in all the groups fell within a narrow range of $0.12-0.17$.

The increased NP/P ratio in lung tissue without pulmonary disease was significant when compared with RDS and atelectasis $(P<0.01$, each) and hemorrhage $(P<0.05)$, but was not significantly different from those with aspiration. The increased ratio among those at term was significant when compared with the two most immature groups, $(P<0.01)$ but was not significantly different when compared with the borderline group $(2,000-2,370 \mathrm{~g})$. In contrast, desmosine proportions were unaffected by either gestational age or disease process.

When matched for weight or gestational age, the expected high correlation of immaturity with RDS or atelectasis was found. The question of whether the low $\mathrm{NP} / \mathrm{P}$ ratio relates more to gestational age or to disease process cannot be categorically answered. Only one infant who had died without pulmonary disease had a birthweight below 2,000 (1,670 g). Its $\mathrm{NP} / \mathrm{P}$ ratio, as well as that of the next smallest newborns in the group $(2,230$ and $2,400 \mathrm{~g})$, was normal $(27,25$, and 24.6 , respectively). In contrast, only three of the infants who died with RDS or atelectasis had birthweights above 2,000 ; one with atelectasis and a weight of 2,370 had an intermediate $\mathrm{NP} / \mathrm{P}$ ratio of 16.5 ; two newborns with RDS and birth weights of 2,150 and 2,050 had NP/P ratios of 5.3 and 5.7. In these cases, therefore, the NP/P ratio correlated more closely with birthweight than with the diagnosis. On the other hand, three infants with RDS and birthweight of 580, 1,270, and 1,340 $\mathrm{g}$ had $\mathrm{NP} / \mathrm{P}$ ratios of $16.2,18.8$, and 19.3 . The relationship of birthweight to $\mathrm{NP} / \mathrm{P}$ ratio for the $15 \mathrm{RDS}$ and the 16 atelectasis cases are listed in Table IV.

The infant's sex or length of survival after birth did not affect the composition of lung tissue elastin. Yields of elastin were determined in 12 cases, 3 in this series and 9 not included because of inadequate histopathology. Based on wet weight before removal of major vessels which were discarded, elastin yields ranged from a low of 0.11 to a high of $2.4 \%$, with an average of $0.73 \%$. Wet weight of tissue samples analysed ranged from 5.4 to $10.8 \mathrm{~g}$ with an average of $7.9 \mathrm{~g}$ and elastin yields from 1 to $13 \mathrm{mg}$, with an average of $5.0 \mathrm{mg}$, giving an average yield of $0.63 \%$. No correlation could be discerned between $\mathrm{NP} / \mathrm{P}$ ratios and percent yield. Elastin recovered from the lungs of the two infants with the lowest NP/P ratios within the group, twins with atelectasis, birthweights of 800 and $1,140 \mathrm{~g}$, respectively, and NP/P ratios of 1.2 and 1.1 , amounted to 0.33 and $0.43 \%$. However, yields associated with the highest $\mathrm{NP} / \mathrm{P}$ ratios, 25.1 and 26.1 , were equally below average, 0.1 and $0.4 \%$

To complement data deduced from the neonatal lung elastin analyses, three abortuses obtained by hysterotomy at $12-14$ wk gestation were studied. Their $\mathrm{NP} / \mathrm{P}$ ratios were very low, $1.4,1.5$, and 2.2 , and, in addition, desmosine plus isodesmosine percentages were greatly reduced, $0.025,0.024$, and 0.027 .

TABLE IV

Relationship of NP/P Ratio to Birthweight in Infants with RDS or Atelectasis

\begin{tabular}{crccc}
\hline \multicolumn{2}{c}{ RDS } & & & \multicolumn{2}{c}{ Atelectasis } \\
\cline { 5 - 5 } \cline { 5 - 5 } Birth weight & NP/P ratio & & Birth weight & NP/P ratio \\
\hline 580 & 16.2 & & 380 & 4.8 \\
700 & 8.1 & & 500 & 1.3 \\
750 & 9.4 & & 595 & 2.1 \\
800 & 14.5 & & 600 & 5.1 \\
1,050 & 15.9 & & 650 & 4.8 \\
1,140 & 9.2 & & 660 & 3.6 \\
1,230 & 2.3 & & 700 & 9.7 \\
1,270 & 6.2 & & 800 & 1.1 \\
1,270 & 18.8 & & 900 & 7.1 \\
1,300 & 5.9 & & 1,050 & 8.6 \\
1,340 & 19.3 & & 1,190 & 5.2 \\
1,360 & 2.1 & & 1,360 & 14.3 \\
1,380 & 10.4 & & 1,400 & 4.8 \\
2,050 & 5.7 & & 1,700 & 10.8 \\
2,150 & 5.3 & & 1,860 & 2.2 \\
& & 2,370 & 16.5 \\
\hline
\end{tabular}




\section{DISCUSSION}

Our data suggest that cross-linkage in lung elastin occurs early in gestation, after 12-14 wk but before $22 \mathrm{wk}$. This timing is comparable to that observed for elastin in the aortic arch of human fetuses by LaBella and Vivian (4). In contrast, the nonpolar ratio does not reach ma. ture values until the $32 \mathrm{nd}$ wk or about the same time at which surfactant maturation occurs (5). In certain cases, the disease process alone appears to be the principal association with a low ratio, while in others, maturity is the more significant association. Since lung disease is almost universal in immature cases, there is no way that the two factors can definitively be separated. No one abnormality alone is sufficient to explain the pathogenesis of RDS. Our data suggest that in certain instances, polar, or immature, elastin is found and may be contributing to the functional abnormalities typical of the disease.

Our finding of relatively high polarity in elastin from human fetal lung is consistent with previous observations in a variety of fetal organs of other species.

A transient component, distinct from the typical nonpolar elastin, may be associated with immature elastin by a covalent bond (6) or by physical aggregation (7). Classical methods of extraction, including boiling with $\mathrm{NaOH}$, are unable to solubilize this component. Two morphologically distinct constituents of mature elastin were first postulated by Ross and Bornstein (8), who separated a microfibrillar polar component from fetal bovine ligamentum nuchae. Valine, glycine, and proline concentration was much lower in this microfibrillar part than in elastin proper. During embryologic development, this component forms first. Albert (9), using a specific electron dense stain, has been able to differentiate the microfibrillar component at the electron microscope level. In developing fetal rat aortas, it appeared early, then decreased in amount, and was completely absent or restricted to the periphery of elastic lamellae as a thin layer in the mature elastic tissue. Robert et al. (7) have shown that the microfibrillar elements of calf ligamentum nuchae are derived from, or are identical with, structural glycoproteins. Another example of polar fetal elastin was observed by Keeley and LaBella (10) in aortas of chickens. As in our study, increasing fetal maturation was associated with decreasing polarity. The authors suggested that the polar component may participate in the elastin monomer assembly in a manner comparable to collagen precursors. Hence, decreased polarity may reflect elastin stabilization required for postnatal pulmonary function.

Increased polarity of infant lung elastin was found previously by Fitzpatrick and Hospelhorn $(11,12)$. The first analyses (11) showed considerably less aspartic acid, glutamic acid, and arginine in elastin from the lung of a 1-mo-old infant than in elastin from adult lungs; but a subsequent paper (12), in which elastins isolated by collagenase digestion instead of alkaline extraction were investigated, showed markedly lower content of glycine and proline and much higher content of acidic and basic amino acids in lung preparations from 4-, 6-, and 18mo-old infants. The changes were, however, less pronounced than those found in fetal lung elastin in the present study. The increases in polarity observed by us in fetal lungs are also substantially greater than those correlated with structural instability in aging and in obstructive lung disease. John and Thomas (13) reported progressively higher concentrations of acid and basic amino acids and less glycine, alanine, and valine with advancing age in elastins extracted from human lung pleura and parenchyma, and two of the present authors (14) found significant decreases in the NP/P ratio of elastin from lungs of adult emphysematous subjects. Similar changes in polarity have also been reported in atheromatous (15) and aging (13) aortas.

\section{ACKNOWLEDGMENTS}

The authors thank Dr. Weiner LeBlanc, Mrs. Yvonne Hosannah, and Miss Mabel Wong for invaluable assistance in carrying out this work.

We also gratefully acknowledge the support of The National Heart and Lung Institute, SCOR Grant HL14218, and Grants from The National Foundation and The New York Tuberculosis and Respiratory Disease Association.

\section{REFERENCES}

1. Evans, H. E., I. Mandl, and S. Keller. 1972. Respiratory distress syndrome: serum enzyme inhibitor levels and lung tissue elastin composition. In Pulmonary Emphysema and Proteolysis. C. Mittman, editor. Academic Press, Inc., New York. 91-99.

2. Evans, H. E., S. Keller, and I. Mandl. 1972. Pulmonary elastin maturation in the human fetus. Am. Rev. Respir. Dis. 105: 1003. (Abstr.).

3. Lansing, A. I., T. B. Rosenthal, M. Alex, and E. W. Dempsey. 1952. The structure and chemical characterization of elastin fibers as revealed by elastase and by electron microscopy. Anat. Rec. 114: 555-570.

4. LaBella, F. S., and S. Vivian. 1967. Amino acid composition of elastin in the developing human aorta. Biochim. Biophys. Acta. 133 : 189-194.

5. Gluck, L., M. Y. Kubovich, A. I. Eidelman, L. Cordero, and A. F. Khazin. 1972. Biochemical development of surface activity in mammalian lungs. IV. Pulmonary lecithin synthesis in the human fetus and newborn and etiology of the respiratory distress syndrome. Pediatr. Res. 6: 81-99.

6. Downie, J. W., F. S. LaBella, and S. Whitaker. 1973. The relationship between elastin and an acidic protein in mammalian uterus. Connect. Tissue Res. 2: 37-48.

7. Robert, B., M. Szigeti, J.-C. Derouette, L. Robert, H. Bouissou, and M.-T. Fabre. 1971. Studies on the nature of the microfibrillar component of elastic fibers. Eur. J. Biochem. 21 : 507-516. 
8. Ross, R., and P. Bornstein. 1969. The elastic fiber. I. The separation and partial characterization of its macromolecular components. J. Cell. Biol. 40: 366-381.

9. Albert, E. N. 1972. Developing elastic tissue. An electron microscope study. Am. J. Pathol. 69: 89-94.

10. Keeley, F. W., and F. S. LaBella. 1972. Amino acid composition of elastin in the developing chick aorta. Connect. Tissue Res. 1 : 113-119.

11. Fitzpatrick, M., and V. D. Hospelhorn. 1962. Studies on human pulmonary connective tissue. I. Amino acid composition of elastins isolated by alkaline digestion. J. Lab. Clin. Med. 60: 799-810.

12. Fitzpatrick, M., and V. D. Hospelhorn. 1965. Studies of human pulmonary connective tissue. II. Amino acid composition of residues following collagenase digestion of lung connective tissues. Am. Rev. Respir. Dis. 92: $792-800$.

13. John, R., and J. Thomas. 1972. Chemical compositions of elastins isolated from aortas and pulmonary tissues of humans of different ages. Biochem. J. 127: 261-269.

14. Keller, S., and I. Mandl. 1972. Qualitative differences between normal and emphysematous human lung elastin. In Pulmonary Emphysema and Proteolysis. C. Mittman, editor. Academic Press, Inc., New York. 251-259.

15. Kramsch, D. M., C. Franzblau, and W. Hollander. 1971. The protein and lipid composition of arterial elastin and its relationship to lipid accumulation in the atherosclerotic plaque. J. Clin. Inv. 50: 1666-1677. 